Field, G. B. (1967). Clin. Sci., 32, 279.

Fletcher, C. M., Hugh-Jones, P., McNicol, M. W., and Pride, N. B. (1963). Quart 3. Med., 32, 33.

Fraser, R. G., and Bates, D. V. (1959). Amer. F. Roentgenol., 82,

Gilson, J. C., and Hugh-Jones, P. (1949). Clin. Sci., 7, 185.

Goldman, H. I., and Becklake, M. R. (1959). Amer. Rev. Tuberc., 79, 457.

Halmagy, D. F., and Cotes, J. E. (1959). Clin. Sci., 18, 475.

Herschfus, J. A., Bresnick, E., and Segal, M. S. (1953). Amer. 7. Med., 14,34 .

Jacoby, N. M. (1966). Lancet, 2, 1354.

Jones, R. S., and Miade, F. (1961). Quart. 7. exp. Physiol., 46, 131.

Kanagami, H., Katsura. T., Shiroishu, K., Baba, K., and Ebina, T. (1961). Acta med. scand., 169, 595.

Knudson, R. J., and Constantine, H. P. (1967). J. appl. Physiol., 22,

Kory, R. C., Callahan, R., Boren, H. G., and Syner, J. C. (1961). Amer. 7. Med., 30, 243.

Kreukniet, J., and Visser, B. F. (1962). Acta physiol. pharmacol. neerl., 11, 386 .

Laws, J. W., and Heard, B. E. (1962). Brit. F. Radiol., 35, 750.
Ledbetter. M. K., Bruck, E., and Farhi, L. E. (1964). J. clin. Invest., $43,2233$.

Lloyd, B. B. (1958). 7. Physiol. (Lond.), 143, 5P

McGrath, M. W., and Thomson, M. L. (1959). Ibid., 146, 572.

Mead, J. (1960). 7. appl. Physicl. 15, 736

Newman, F. (1963). Ph.D thesis, University of London.

Ogilvie, C. M., Forster, R. E., Blakemore, W. S., and Morton, J. W. (1957). \%. clin. Invest., 36, 1.

Piiper, J., and Sikand, R. S. (1966). Resp. Physiol., 1, 75.

Rackemann, F. M. (1947). Amer. F. Med., 3, 601.

Riley, R. L., and Cournand, A. (1949). F. appl. Physiol., 1, 825.

Severinghaus, J. W., and Stupfel, M. (1957). Ibid., 10, 335.

Shanks, R. G., Brick, 1., Hutchison, K., and Roddie, 1. C. (1967). Brit. med. 7., 1, 610 .

Tai, E., and Read, J. (1967). Lancet, 1, 644

Thomson, W. B., and Hugh-Jones. P. (1958). Brit. med. 7., 1, 1093.

Vries, K. de Tammeling, G. J., Orie, N. G. (1962). Ned.' T.' Geneesk. 106, 2295 .

West, J.' B., Fowler, K. T., Hugh-Jones, P., and O'Donnell, T. V. (1957). Clin. Sci., 16. 329. Williams, M. H., iun., and Zohman, L. R. (1959). Amer. Rev. resp. Dis.,
80, 689.

Woolcock, A. J., and Read, J. (1966). Amer. J. Med., 41, 259.

\title{
Some Clinical Aspects of Respiratory Intensive Care
}

\author{
DONALD CAMPBELL,* M.B., CH.B., D.A., F.F.A. R.C.S.; J. M. REID,* M.B., CH.B., D.A., F.F.A. R.C.S.
}

A. B. M. TELFER,* M.B., CH.B., F.F.A. R.C.S. ; W. FITCH,† M.B., CH.B., B.SC., D.OBST.R.C.o.G., F.F.A. R.C.S.

Brit. med. Y., 1968, 1, 475-477

In a recent paper (Campbell et al., 1967) the general problems involved in the organization of a respiratory intensive care unit in the Glasgow Royal Infirmary were discussed. In addition the various categories of patients treated in the unit were outlined. This communication represents a more detailed analysis of 202 of these patients suffering from respiratory insufficiency after elective and emergency surgery.

\section{Postoperative Respiratory Problems}

Two hundred and two patients were treated in the intensive care unit after elective or emergency surgery. Though a proportion of them could be classified more properly as " 24 -hour recovery cases" they were of necessity admitted owing to a shortage of routine postoperative recovery facilities in this

Tablr I.-Analysis, According to Age, of 131 Elective Surgical Patients who Developed Postoperative Respiratory Insufficiency. Ratio of Males to Femates $=1.7: 1$. Overall Survival Rate: Males $85.6 \%$, Pemales 78.7\%

\begin{tabular}{|c|c|c|c|c|}
\hline \multirow{2}{*}{ Decade } & \multicolumn{2}{|c|}{ No. of Patients } & \multicolumn{2}{|c|}{$\%$ Survival } \\
\hline & Male & Female & Male & Female \\
\hline $\begin{array}{r}1 \\
2 \\
3 \\
4 \\
5 \\
6 \\
7 \\
8 \\
9 \\
10\end{array}$ & $\begin{array}{l}1 \\
1 \\
3 \\
99 \\
20 \\
32 \\
18 \\
=\end{array}$ & $\begin{array}{l}\frac{1}{1} \\
\frac{1}{6} \\
15 \\
12 \\
10 \\
2 \\
-\end{array}$ & $\begin{array}{l}100 \\
100 \\
100 \\
89 \\
95 \\
75 \\
89 \\
=\end{array}$ & $\begin{array}{r}100 \\
100 \\
100 \\
67 \\
67 \\
80 \\
50\end{array}$ \\
\hline
\end{tabular}

hospital. Nevertheless, the average length of stay was 4.1 days, a figure which suggests that on the whole these patients would have required prolonged postoperative care even if immediate recovery facilities had been available.

- Consultant Anaesthetist, Royal Infirmary, Glasgow C.4.

+ Registrar Anaesthetist. Royal Infirmary, Glasgow C.4. Present address : University Department of Anaesthesia, Western Infirmary, Glasgow W.1.
It is of some interest to compare those patients admitted after elective surgery with those admitted after emergency surgery. The latter group might be expected to show considerable differences from the elective cases in that, as a general rule, there was little time or opportunity preoperatively to carry out the most thorough respiratory investigations or preparatory therapy. Tables I and II compare the two groups of patients from the point of view of distribution of ages. The numbers

TABLE II.-Analysis, According to Age, of 71 Emergency Surgical Patients Who Developed Postoperative Respiratory Insufficiency. Ratio of Mules to Females =2.5:1. Overall Survival Rate : Males $68.6 \%$, Females $50 \%$

\begin{tabular}{|c|c|c|c|c|}
\hline \multirow{2}{*}{ Decade } & \multicolumn{2}{|c|}{ No. of Patients } & \multicolumn{2}{|c|}{ \% Survival } \\
\hline & Male & Female & Male & Female \\
\hline$\frac{1}{2}$ & $\overline{1}$ & $=$ & $1 \overline{100}$ & $\overline{-}$ \\
\hline $\begin{array}{r}4 \\
5 \\
6 \\
7 \\
8 \\
8 \\
9 \\
10\end{array}$ & $\begin{array}{r}1 \\
4 \\
13 \\
23 \\
7 \\
3 \\
\end{array}$ & $\begin{array}{l}1 \\
4 \\
3 \\
9 \\
2 \\
\\
\end{array}$ & $\begin{array}{r}100 \\
50 \\
77 \\
61 \\
71 \\
67 \\
-\end{array}$ & $\begin{array}{r}100 \\
50 \\
100 \\
44 \\
0 \\
=\end{array}$ \\
\hline
\end{tabular}

of patients, both male and female, are shown, together with the percentage survival rates for each decade. The overall survival rates are better for the males in both elective and emergency categories. The ratio of males to females is slightly higher in the emergency cases. The Tables otherwise show a strikingly similar distribution of patients, with the bulk of cases occurring in the fifth to eighth decades.

Tables III and IV (131 elective cases and 71 emergency cases) indicate the major disturbance of normal function in each patient, though all presented initially as respiratory problems. The main problems can be classified under metabolic, cardiovascular, pre-existing chronic lung disease, and those involving the relaxant drugs. Where more than one major disorder was identified in one patient, the individual is classified under each heading. 

TABLE III.-Analysts of 131 Elective Surgical Cases Indicating the Main
Underlying Disorders, Though All Patients Initially Presented as Acute Respiratory Disturbances. The Last T200 Categories Represent the Number of Elective Cases in Which it $W$ as Difficult Determine Whether the Metabolic Disturbance Preceded or Followed a Period of Cardiovascular or Respiratory Depression

\begin{tabular}{|c|c|c|c|}
\hline & No. of Cases & Survivals & $\%$ Survival \\
\hline 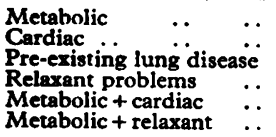 & $\begin{array}{r}39 \\
36 \\
43 \\
3 \\
20 \\
12\end{array}$ & $\begin{array}{r}25 \\
21 \\
32 \\
3 \\
10 \\
11\end{array}$ & $\begin{array}{r}64 \\
58 \\
74 \\
100 \\
50 \\
92\end{array}$ \\
\hline
\end{tabular}

Table IV.-Analysis of 71 Emergency Surgical Cases Indicating the Main Underlying Disorders, Though AII Patients Presented Initially as Cases of Acute Respiratory Disturbance. The Last Two Categories are as in Table III

\begin{tabular}{|c|c|c|c|}
\hline & No. of Cases & Survivals & $\%$ Survival \\
\hline $\begin{array}{ll}\text { Metabolic } & \ldots \\
\text { Cardiac } & \ldots \\
\text { Pre-existing lung disease } \\
\text { Relaxant problems } \\
\text { Metabolic + cardiac } \\
\text { Metabolic + relaxant } \quad \ldots\end{array}$ & $\begin{array}{r}27 \\
19 \\
31 \\
5 \\
11 \\
14\end{array}$ & $\begin{array}{r}18 \\
10 \\
14 \\
5 \\
8 \\
8\end{array}$ & $\begin{array}{c}67 \\
53 \\
45 \\
100 \\
72 \cdot 7 \\
57\end{array}$ \\
\hline
\end{tabular}

Those patients with a metabolic upset were so designated if there was definite evidence-for example, a deviation in base excess beyond $\pm 2 \mathrm{mEq} /$ litre or an electrolytic disturbance, or both. Most patients admitted with a respiratory problem apparently implicating the relaxant group of drugs were on examination classified in one of the other groups. Only those remaining (about $3 \%$ in the elective group and $7 \%$ in the emergency group) were classified as relaxant problems, and all survived, requiring merely prolonged assistance to ventilation. Only three cases of true suxamethonium apnoea were identified. It has been our experience that " relaxant problems" commonly arise from unrecognized disturbances of metabolic, cardiovascular, or respiratory function.

The other groups were determined by assessment of the patient's history and clinical examination as well as radiographic and electrocardiographic findings. In this series there were instances where it was difficult to determine whether an upset in acid-base balance actually preceded rather than followed a period of cardiovascular depression or respiratory insufficiency. These cases are enumerated separately in Tables III and IV.

On examining the results from those patients with a definite cardiological background-for example, widespread cardiovascular disease, history of embolic or thrombotic episodes, etc. - a rather more surprising result is obtained. The numbers involved, both electively and in emergency surgery, are almost identical (nearly $30 \%$ of all cases), but the survival rate is only slightly better in the elective cases (58\% as against $53 \%$ ). The explanation is not at first clear, but it is possible that $a$ high mortality is to be expected in all those patients coming to surgery, whether elective or not. On the other hand, it is conceivable that the concentration of effort on the preoperative preparation of known pulmonary disorders is resulting in a comparative neglect of the preparation of patients with underlying cardiovascular disease destined for major surgery. One practical point which has also emerged is that it may well be relevant to consider the wisdom of preoperative digitalization of elderly patients with demonstrable heart disease, cven in the absence of congestive cardiac failure. This policy has indeed been advocated by Christiansen and Brøckner (1967).

A similar situation is encountered on comparison of the two metabolic groups. Again the proportion of total cases is alike in the elective and emergency groups (30 to $40 \%$ of all cases), and again the mortality rates are little different.

On reflection it can be seen that only in the group with pre-existing lung disease is the survival rate strikingly better for the elective cases. This again suggests that these patients receive more attention so far as preparatory assessment and therapy are concerned. If we are to advance from the present purely conjectural position there is no doubt that mere complete preoperative investigation of all patients, and more adequate monitoring of vital functions in the theatre, are necessary. Unless they are achieved no elucidation of these and like problems of patient care will be possible.

\section{Importance of Measurement}

The inescapable impression from scrutiny of these simple statistics is that some of the patients need not have required intensive postoperative therapy if a more precise preoperative assessment had been possible. Again, some patients, if observed and perhaps monitored more closely in the immediate postoperative period, might also have been able to avoid admission to the intensive care unit. The latter counsel is, of course, one of perfection, and it is not usually possible, with staff shortages, etc., to provide this degree of individual care outside of a postoperative recovery room or an intensive care unit. This point is well illustrated in the matter of the use of oxygen therapy. Despite the fact that the theory of oxygen availability was propounded almost 25 years ago by Richards (1943-4), this is still probably the most misused of all drugs in clinical practice. Usually this is because of the unavailability of apparatus to assess arterial oxygen tension or to measure precisely the actual inspired concentration from whatever mask is employed. While such measurements are invaluable, it $t$ still possible to attempt a more logical approach to oxygeo therapy and to introduce an element of control by the use of quite simple apparatus.

Flenley et al. (1963) described the Edinburgh mask for the control of oxygen dosage at low concentrations according to the flow rate supplied. This basic mask can easily be modified by the addition of detachable $200-\mathrm{ml}$. reservoirs to supply higher concentrations for the postoperative patient. By adjustment of oxygen flow and reservoir size and measurement of the patient's minute-volume any desired inspired concentration of the gas can be achieved (see Fig.). It is also possible

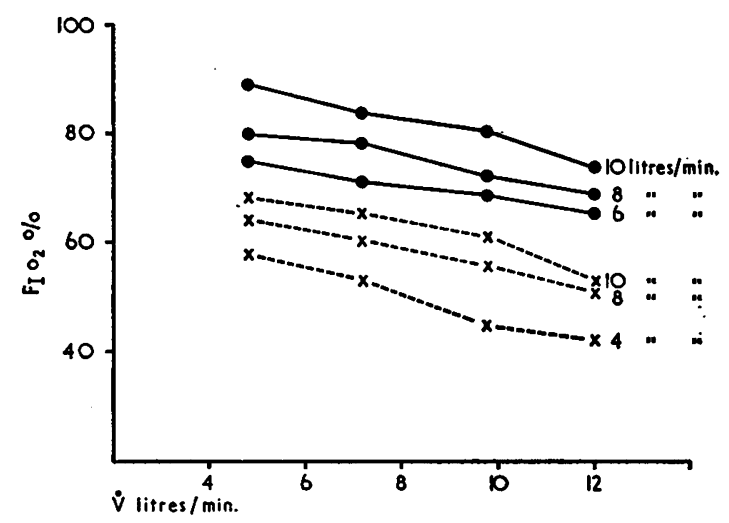

Performance of modified Edinburgh mask is shown fo: different minute-volumes and at different oxygen for rates. The solid lines indicate the performance in terms of the attained inspired oxygen concentration ( $\left.\mathrm{F}_{\mathrm{O}} \mathrm{O}_{\mathrm{j}}\right)$ with $400-\mathrm{ml}$ reservoir attached to the mask. The wroken lines indicate the performance when the reservoir volume is reduced to $200 \mathrm{ml}$. It is possible to select the appropriate reservoir and oxygen flow rate for any patient to deliver the desired orygen concentr
tion, provided the minute-volume is known $(\dot{V})$.

to "wean" the patient progressively from high to low con. centrations rather than the more common "all-or-nothing" technique. This open T-piece system has also the additional safety feature of "failing safe" should the oxygen flow be inadvertently turned down or off. The serial measurement of arterial oxygen tension, where possible, gives complete control of oxygen administration with this technique.

Another example of the importance of measurement as a guide to therapy is in the provision of adequate relief of pain 
in the immediate postoperative period, especially in patients with respiratory insufficiency. The various techniques which may be employed, particularly in patients on ventilator therapy, have been fully discussed by Campbell (1967). Here again arterial blood gas analysis, along with careful monitoring of the heart rate, systemic blood pressure, and pulse pressure, is an invaluable guide when there is either unrelieved pain or oversedation with narcotic analgesics.

It is one of the important functions of an intensive care unit to initiate and develop methods of therapy such as those described above, many of which are applicable outside the intensive care area. Another function is to "feed back" information such as that revealed in the comparison of elective and emergency postoperative cases, already discussed, in order that new approaches to their treatment may be considered, as this can be done only where the problem is recognized and measured.

\section{Conclusion}

In a previous communication the experience of four years of respiratory intensive care in a large teaching hospital was reported. The present communication has amplified this in respect of more detailed comment on some of the clinical problems encountered in the intensive care of 202 postoperative patients. The value of a critical analysis of this nature cannot be overstressed in view of the fact that intensive care units of this type are increasing in number throughout the United Kingdom, yet there is a paucity of published work on the organizational aspects of the problem to guide clinicians. Recently a B.M.A. (1967) working party has undertaken a study in selected units throughout the country in an attempt to define the aims of such units and to give a factual basis for estimating their accomplishments and work. In our own experience (five years at October 1967) of respiratory intensive care the unit at the Glasgow Royal Infirmary has proved its worth in terms of improved standards of patient care, and, in addition, has revealed clinical problems which demand further investigation to explain. The unit provides an excellent opportunity to evaluate new methods of therapy, and indeed to compare the efficacy of existing methods under controlled conditions. A useful method of controlled oxygen therapy employing a simple basic mask has been developed in this way for use in the postoperative period.

\section{Summary}

Two hundred and two patients were treated in the respiratory intensive care unit at Glasgow Royal Infirmary after elective and emergency surgery. The average length of stay was 4.1 days. One hundred and thirty-one patients were admitted after elective and 71 after emergency surgery and the two groups were compared. In each group there were more males than females $(1.7: 1$ in the elective group and 2.5:1 in the emergency group) and the overall survival rates favoured the male patients. Many of the patients were found to have important underlying metabolic and cardiac disturbances, and the mortality rates in these patients differed little in the elective and emergency groups. It is suggested that a preoccupation with pre-existing respiratory problems resulted in a comparative neglect of important cardiovascular and metabolic features. Preoperative digitalization is suggested for many elderly patients with demonstrable cardiac disease even when there is no evidence of congestive failure.

REFERENCES

British Medical Association (1967). Planning Unit Report, No. 1 Campell D. (1967). Brit. \%. Anaesth., 39, 736.

Campbel, D. J. M., Telfer, A. B. M., and Fitch, W. (1967). Brit. med. Y, 4,255 .

Christiansen, J., and Brøckner, J. (1967). Dais. med. Bull., 14, 38.

Flenley, D. C., Hutchison, D. C. S., and Donald, K. W. (1963). Brit. med. $₹ ., 2,1081$.

Richard3, D. W. (1943-4). Harvey Lect., 39, 217.

\title{
Effects of Emotion and Pain on Adrenocortical Function Investigated by Hypnosis
}

\author{
STEPHEN BLACK, * M.R.C.S., L.R.C.P. ; MAX FRIEDMAN, $†$ M.B., B.CH., M.R.C.P.ED.
}

Brit. med. F., 1968, 1, 477-481

In a group of hospital patients with suspected adrenal disease it was found that when the plasma levels of 11-hydroxycorticosteroids (plasma cortisol) were estimated in the same patient at the same hour on different days variations occurred which suggested that the mental state of the patient must be taken into account in any assessment of adrenal function by this means. In all patients in this group the plasma cortisol levels were found to be higher during the first few days after admission to hospital than they were afterwards, and the levels were highest in those patients who appeared to be most anxious as a result of their admission (Friedman, 1965).

Among their many functions the adrenals are apparently concerned with the general response of the body to noxious stimuli, and a wide variety of stressful situations are now known to evoke increased production of cortisol by the adrenal cortex in response to adrenocorticotrophic hormone (A.C.T.H.) released by the anterior pituitary. However, the precise mechanisms involved in the release of A.C.T.H. are still obscure, though known to be under hypothalamic control-possibly by way of pathways from higher cortical centres (Schally et al., 1960). In the intact and unanaesthetized animal stress usually involves emotion, and emotion alone can be stressful, so that, although for experimental purposes in man it may be useful to equate stress with pain, heat, and cold, or the administration of pyrogens, or insulin-induced hypoglycaemia (Landon et al. 1963 ; Wexler et al., 1957), the role of emotion should also be taken into account when considering adrenocortical function.

Investigation of the effects of emotion has always presented difficulties in both psychology and physiology because of the problem of establishing controlled and repeatable experimental conditions; and, with regard to anxiety in man, workers in this field have tended to find their source material among such individuals as examination candidates and American rowing eights (Hill et al., 1956). However, a number of different modalities of emotion-including anxiety-can apparently be produced under controlled and repeatable experimental conditions in suitable deep-trance hypnotic subjects by hypnotic suggestion.

\footnotetext{
- Director of a Research Unit in Psychophysiology under the Nuffield Foundation at 43 Wilton Crescent, London S.W.1 t Senior Paediatric Registrar, University College Hospital, London W.C.1.
} 